\title{
Tricuspid component of first heart sound
}

\author{
J. B. Lakier, K. R. Bloom, W. A. Pocock, and J. B. Barlow \\ From the Cardio-Vascular Research Unit, Department of Medicine, University of the Witwatersrand; and the \\ Cardiac Clinic, General Hospital, fohannesburg, South Africa
}

\begin{abstract}
Right and left atrial pressures with a simultaneous external phonocardiogram and standard lead II electrocardiogram were recorded during routine cardiac catheterization in 15 patients. With one exception, the onset of the second $\left(T_{1}\right)$ major component of the first sound coincided with the peak of the right atrial $c$ wave jusi as the major left-sided component $\left(M_{1}\right)$, previously studied in this laboratory, coincides with the peak of the left atrial $c$ wave. Right and left atrial $c$ waves were synchronous in the exception and in that instance separate major components were not identified. These observations provide further evidence that $T_{1}$ arises at the tricuspid valve. Analogous to the mode of production of $M_{1}$, it is believed that after tricuspid valve closure the apposed leaflets are billowed into the right atrial cavity resulting in right atrial $c$ waves, at the peak of which tension on the chordae tendineae and leaflets themselves produces $T_{1}$. Some factors affecting the timing and intensity of $M_{1}$ and $T_{1}$ are mentioned.
\end{abstract}

The mechanism of production and factors influencing the timing and intensity of the major left-sided component $\left(M_{1}\right)$ of the first heart sound have been studied and discussed in recent publications from this laboratory (Lakier et al., 1972a, b, c). It was concluded that the mitral leaflets appose and the valve 'closes' at the point of crossover of the left ventricular and left atrial pressures but that $\mathbf{M}_{1}$, which is almost always the earlier of the two major first sound components, occurs after the valve has closed. $M_{1}$ is caused by maximal tension on the coapted leaflets and the chordae tendineae at the peak of the ascent of the leaflets into the left atrial cavity. The billowing of the apposed leaflets produces the left atrial $c$ wave, at the peak of which vibrations of $M_{1}$ can be seen to begin on a simultaneously recorded phonocardiogram. There are several important factors which affect the timing and intensity of $M_{1}$ as well as the amplitude of the left atrial c wave (Lakier et al., 1972a). These include mitral leaflet size and the mobility of the valve mechanism. $M_{1}$ and the peak of the left atrial $c$ will be delayed, with $M_{1}$ louder and the left atrial $c$ of larger amplitude, when the leaflets are relatively more voluminous or the valve mechanism more mobile (Lakier et al., 1972b).

Although it is widely believed that the other major component of the first sound, which nearly Received 19 April 1973.

1 This study was supported in part by The South African Medical Research Council. always follows $M_{1}$, is produced at the tricuspid valve (Leatham, 1954, 1970; Heintzen, 1961 ; Haber and Leatham, 1965; Rees, Farru, and Rodriguez, 1972), this concept has been disputed (di Bartolo et al., 196I; Shah et al., 1963; Delman, 1967; Luisada et al., 197r). The present study was, therefore, undertaken to ascertain whether this second major component $\left(T_{1}\right)$ has the same time relation to the peak of the right atrial $\mathrm{c}$ wave as does $M_{1}$ to the left atrial $c$ wave. Factors affecting the timing and intensity of $T_{1}$, as well as the amplitude of the right atrial c, are briefly discussed.

\section{Subjects and methods}

Using methods similar to those previously described from this laboratory (Lakier et al., 1972a, c), an electrocardiogram, external phonocardiogram, and simultaneous left atrial and left ventricular pressures were recorded during routine cardiac catheterization in Io patients, 2 with aortic and 8 with mitral valve disease (Table). In addition, the right atrial pressure was recorded through the Brockenbrough catheter immediately before perforation of the atrial septum. Consecutive right atrial, right ventricular, and left atrial pressures were recorded through a $7 \mathrm{~F}$ Rodriguez Alvarez catheter in 4 patients with an atrial septal defect of the secundum type. Simultaneous left and right atrial pressures were obtained through two such catheters in one subject in whom cardiac catheterization revealed a diagnosis of 'straight back syndrome' (Rawlings, 1960; de Leon et al., 1965) with an associated patent foramen ovale but an otherwise normal heart. 
In all instances, phonocardiograms were recorded at a site between the left sternal border and apex at which both major components of the first sound could be demonstrated. Delay between the phonocardiographic and pressure recordings has previously been shown to be negligible (Lakier et al., I972a) and can be ignored.

\section{Results}

With one exception (Case 8, Table), both major components of the first sound were demonstrated phonocardiographically and the onset of $T_{1}$ coincided with the peak of right atrial c. The interval between $\mathrm{Q}$ of the simultaneous electrocardiogram and $T_{1}$ (or right atrial c) ranged from 0.07 to $0.10 \mathrm{sec}$ (Table). In the subject with the straight back syndrome and normal heart (Fig. I), the 4 patients with an atrial septal defect, and 7 of the ro with valvular disease, the $\mathrm{Q}-\mathrm{T}_{1}$ (right atrial c) interval exceeded that of $\mathrm{Q}-\mathrm{M}_{1}$ (left atrial c). However, in

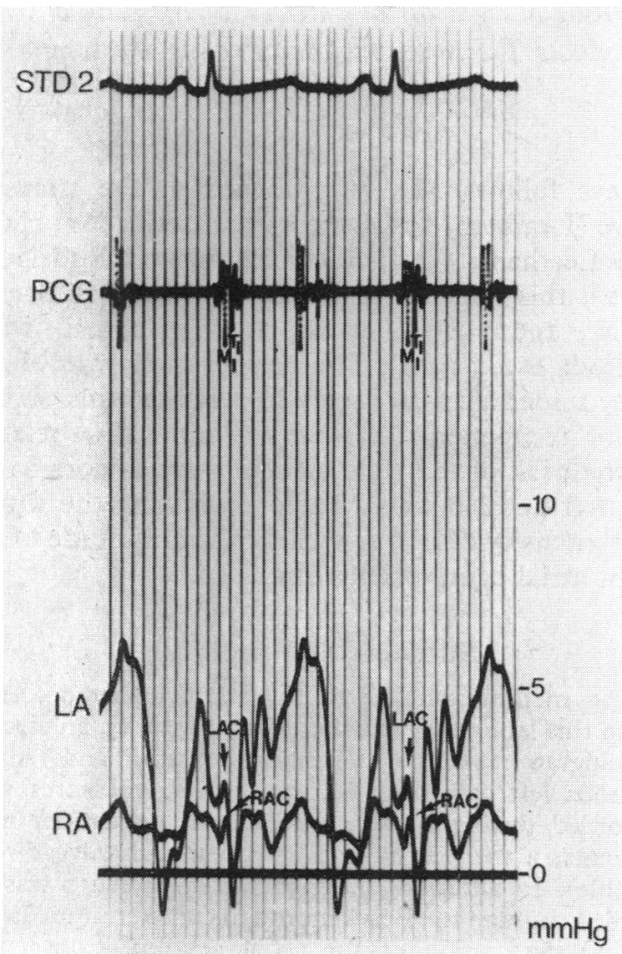

FIG. I Simultaneous electrocardiogram, phonocardiogram, left atrial $(L A)$, and right atrial $(R A)$ pressure tracings in the patient (Case 15, Table) with a normal heart and the straight back syndrome. $M_{1}$ and the peak of left atrial $c$ precede the peak of right atrial $c$ and $T_{1}$ by $0.02 \mathrm{sec}$. See text. Time lines 0.04 sec.

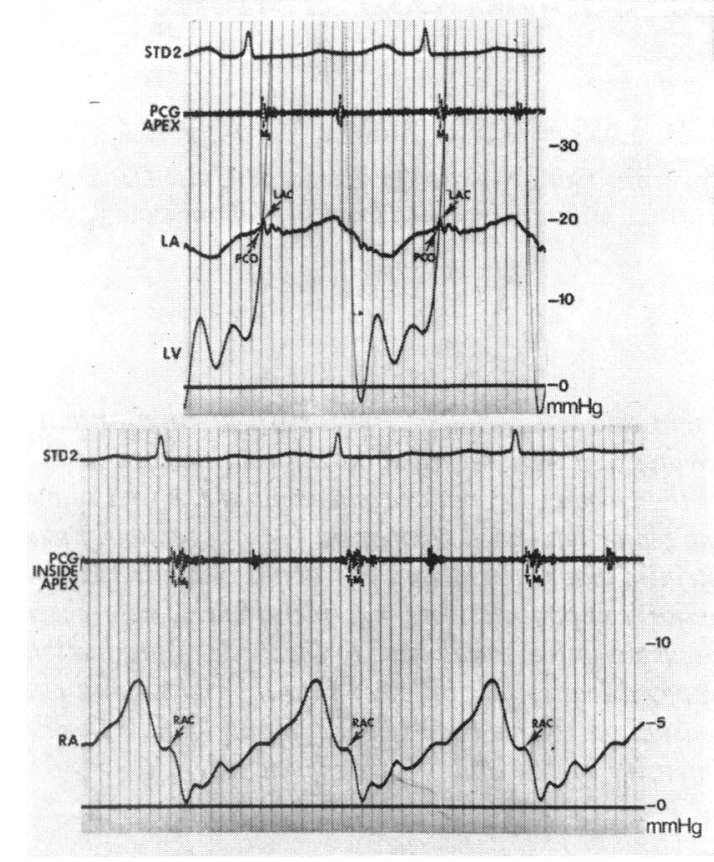

FIG. 2 Reversal of the major components of the first sound in a patient (Case 9, Table) with very tight mitral stenosis. It can be seen in the top tracing, in which the phonocardiogram is recorded at the apex, that $M_{1}$ and the synchronous left atrial c peak occur almost immediately after the crossover (PCO) of $L A$ and $L V$ pressures. On the lower tracing, with the phonocardiogram recorded inside the apex, the vibration $T_{1}$ which starts at the peak of the right atrial $c$ is shown to precede $M_{1}$.

the 2 patients with very tight mitral stenosis (Cases 9 and Io, Table), the Q- $M_{1}$ (left atrial c) interval was prolonged to $0 \cdot 10 \mathrm{sec}$ whereas the $\mathrm{Q}-\mathrm{T}_{1}$ (right atrial c) intervals were shorter. In both instances, therefore, the major components of the first sound were reversed (Fig. 2). The patient (Case 8, Table) in whom $M_{1}$ and $T_{1}$ did not record separately had mixed mitral regurgitation and stenosis and the peaks of left atrial c and right atrial c were synchronous.

In all 4 patients with an atrial septal defect left atrial $c$ was of smaller amplitude than right atrial $c$ and the intensity of $M_{1}$ was less than that of $T_{1}$ (Fig. 3).

\section{Discussion}

Good evidence for a tricuspid origin of the second major first sound component $\left(T_{1}\right)$ was provided by 
TABLE Summary of data from 15 patients

\begin{tabular}{clll}
\hline Case No. & Diagnosis & \multicolumn{2}{c}{ Time intervals (sec) } \\
& & $Q-M_{1}(L A C)$ & $Q-T I(R A C)$ \\
\hline I & Aortic stenosis & 0.065 & 0.09 \\
2 & Aortic stenosis & 0.065 & 0.10 \\
3 & Mitral stenosis & 0.07 & 0.09 \\
4 & Mitral stenosis & 0.07 & 0.08 \\
5 & Mitral stenosis & 0.07 & 0.10 \\
6 & Mitral incompetence & 0.06 & 0.07 \\
7 & Mitral incompetence & 0.06 & 0.09 \\
$8^{\star}$ & Mitral stenosis and incompetence & 0.07 & 0.07 \\
9 & Tight mitral stenosis & 0.10 & 0.07 \\
I0 & Tight mitral stenosis & 0.10 & 0.09 \\
II & Atrial septal defect & 0.07 & 0.10 \\
I2 & Atrial septal defect & 0.05 & 0.08 \\
I3 & Atrial septal defect & 0.06 & 0.08 \\
I4 & Atrial septal defect & 0.05 & 0.08 \\
I5 & 'Straight back syndrome' & 0.07 & 0.09 \\
\end{tabular}

* Separate major components were not identified but left atrial c (LAC) and right atrial c (RAC) were synchronous-see text.

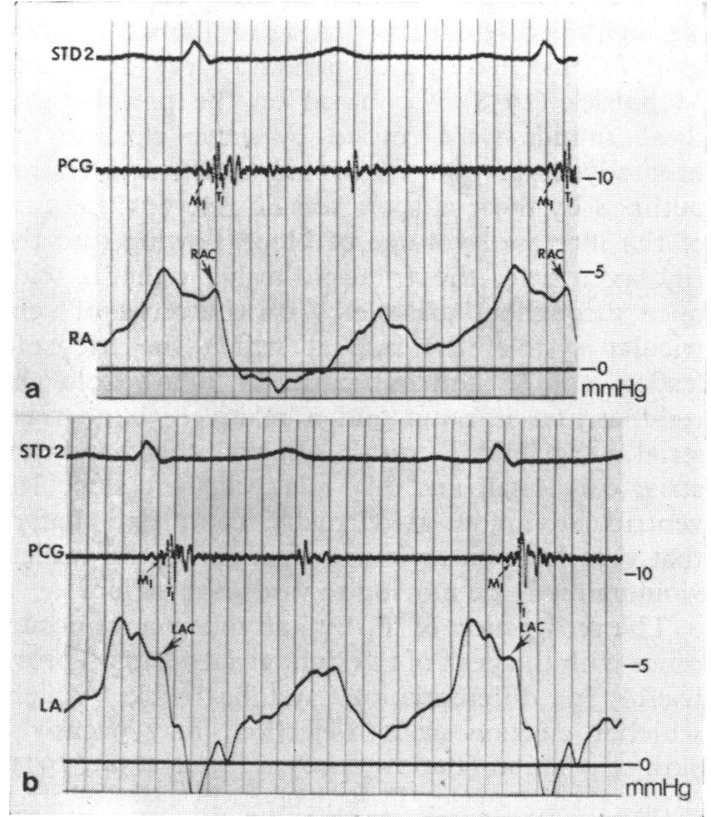

FIG. $3 A$ patient (Case 13, Table) with an atrial septal defect. (a) The relatively loud $T_{1}$ is synchronous with the peak of the right atrial c. (b) $M_{1}$ is soft and the left atrial $c$ of small amplitude. For explanation, see text.
Heintzen's observations (196I) on its movement and changes in intensity during respiration and after the Valsalva manoeuvre. Haber and Leatham's (1965) findings in asynchronous ventricular contraction associated with right bundle-branch block, ectopic beats, and cardiac pacing supported this concept. However, the audibility of a right-sided component has been refuted (di Bartolo et al., I96I; Shah et al., 1963; Luisada et al., 1967; Delman, 1967; Van Bogaert, 1968; Sainani et al., 1968), and Luisada et al. apparently still believe (197I) that the major first sound components arise in the left ventricle and aorta.

Just as the onset of $M_{1}$ was shown to coincide with the peak of the left atrial $c$ in our studies of the mitral components of the first heart sound (Lakier et al., 1972a, b, c), so a similar time relation between $T_{1}$ and right atrial $c$ has been confirmed in this investigation. One of the arguments against the second major component arising on the right side of the heart is based on evidence (di Bartolo et al., 196r; Shah et al., I963; Luisada et al., 197I) that tricuspid valve closure and the onset of right ventricular contraction precede this vibration by a variable time interval. However, and analogous to the mechanism of production of $M_{1}$, it should be emphasized that it is not tricuspid closure which produces $T_{1}$ but the maximal tension on the apposed leaflets, and their chordae, at the limit of their ascent into the right atrial cavity. It is theoretically possible that a true tricuspid 'closure' sound precedes $T_{1}$, but this would usually be obscured by vibrations arising at the mitral valve.

As was expected, $M_{1}$ preceded $T_{1}$ in the majority 


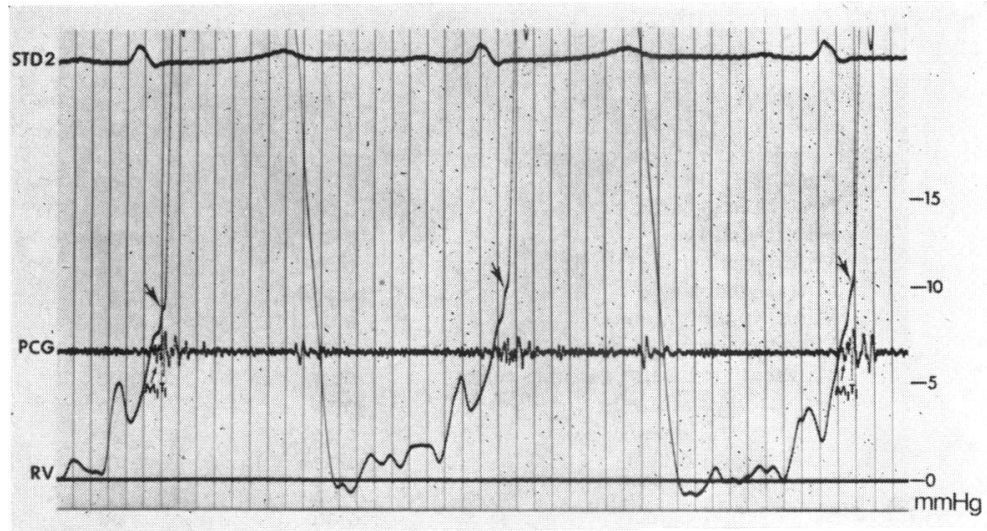

FIG. 4 Right ventricular pressure (RV) of the same patient (Case 13, Table) as in Fig. 2. $T_{1}$ coincides with the change (see arrows) in the rate of rise of the pressure.

of patients in this study (Table). However, the first sound was single in one instance and the peaks of left atrial and right atrial $c$ were then synchronous. In the 2 patients with very tight mitral stenosis, left atrial $c$ and $M_{1}$ were delayed to $0 \cdot 10 \mathrm{sec}$ and occurred after the right atrial $c$ and $T_{1}$. The components of the first sound were thus reversed, a feature that has previously been recognized in tight mitral stenosis (Leatham, 1954; Hultgren and Leo, 1958; Leatham, 1970) and left atrial myxoma (Goodwin et al., 1962).

In their investigation of sound and pressure events in mitral stenosis, Wooley et al. (1968) observed that $M_{1}$ and the left atrial c coincided with the onset of an increased rate of rise of left ventricular pressure. This feature was readily apparent to us during our previous studies (Lakier et al., 1972a, c) and is invariably present when the mitral leaflets are voluminous and the valve mechanism mobile. A similar observation (Fig. 4) can often be made on the right side of the heart. It is understandable that the rate of ventricular pressure rise should increase during the isovolumetric contraction phase from the time that the slack in the atrioventricular valve has been taken up. The point at which this change in ventricular pressure rise occurs is thus contributory in identifying the relevant major component of the first sound. Pocock, Tucker, and Barlow (1969), for example, noted that the increased rate of rise of right ventricular pressure in Ebstein's anomaly coincided with a loud early systolic sound and postulated that the sound arose at the tricuspid valve, an hypothesis confirmed by both Fontana and Wooley (1972) and Crews et al. (1972).

The association of a soft $M_{1}$ and loud $T_{1}$ in atrial septal defect has previously been recognized
(Leatham and Gray, 1956; McKusick, 1958; Lopez, Linn, and Shaffer, 1962), and Rees et al. (1972) have recently claimed that there is a correlation between the delay in $T_{1}$ and the magnitude of the shunt. We were impressed by the relatively small amplitude of the left atrial c compared to that of the right atrial $c$ in our 4 patients with atrial septal defect. Though the original explanation for the soft $M_{1}$ and loud $T_{1}$ provided by Leatham and Gray (1956) and McKusick (1958) was based on the premise that these sounds were caused by valve closure, the haemodynamic and functional anatomical events outlined by those authors remain relevant. Because of the increased volume of blood flowing into the right ventricle, the tricuspid valve remains wide open throughout diastole. With the onset of ventricular systole, the rate at which the tricuspid leaflets appose and subsequently billow into the right atrium is rapid and a relatively large right atrial $c$ and loud $T_{1}$ result. On the other hand, left atrial $c$ is small and $M_{1}$ relatively soft since left ventricular inflow is virtually completed before that ventricle contracts and thus the mitral leaflets would already be moving towards apposition.

The recognition of $T_{1}$ by its synchronous occurrence with the peak of the right atrial $c$ should prove useful in differentiating systolic clicks which, whether ejection or non-ejection, may occupy a similar position (Barlow, 1965; Hutter et al., 197I) in the cardiac cycle. $T_{1}$ is delayed in cases of atrial septal defect (Rees et al., 1972) and it has been observed (Pocock and Barlow, 1971; McDonald et al., 197I) that non-ejection systolic clicks are not uncommonly associated with that congenital cardiac malformation. Should such a click occur early in systole, its time relation to the peak of right atrial c 
would serve to distinguish it from $T_{1}$. It was in this way that we were recently able to identify an early non-ejection click associated with a submitral left ventricular aneurysm (Kanarek et al., 1973).

We wish to thank Dr. H. M. Salmon, Superintendent of the Johannesburg General Hospital, for permission to publish.

\section{References}

Barlow, J. B. (1965). Conjoint clinic on the clinical significance of late systolic murmurs and non-ejection systolic clicks. Fournal of Chronic Diseases, 18, 665.

Crews, T. L., Pridie, R. B., Benham, R., and Leatham, A. (1972). Auscultatory and phonocardiographic findings in Ebstein's anomaly. Correlation of first heart sound with ultrasonic records of tricuspid valve movement. British Heart fournal, 34, 68I.

de Leon, A. C., Perloff, J. K., Twigg, H., and Majd, M. (1965). The straight back syndrome. Clinical cardiovascular manifestations. Circulation, 32, 193.

Delman, A. J. (1967). Hemodynamic correlates of cardiovascular sounds. In Annual Review of Medicine, Vol. 18, p. 139. Ed. by A. C. de Graff and W. P. Creger. Annual Reviews, Palo Alto, California.

di Bartolo, G., Nunez-Dey, D., Muiesan, G., MacCanon, D. M., and Luisada, A. A. (1961). Hemodynamic correlates of the first heart sound. American fournal of Physiology, 201, 888.

Fontana, M. E., and Wooley, C. F. (1972). Sail sound in Ebstein's anomaly of the tricuspid valve. Circulation, 46, 155.

Goodwin, J. F., Stanfield, C. A., Steiner, R. E., Bentall, H. H., Sayed, H. M., Bloom, V. R., and Bishop, M. B. (1962). Clinical features of left atrial myxoma. Thorax, 17, 91.

Haber, E., and Leatham, A. (1965). Splitting of heart sounds from ventricular asynchrony in bundle-branch block, ventricular ectopic beats, and artificial pacing. British Heart fournal, 27, 691.

Heintzen, P. (196I). The genesis of the normally split first heart sound. American Heart fournal, 62, 332.

Hultgren, H. N., and Leo, T. F. (1958). The tricuspid component of the first heart sound in mitral stenosis. Circulation, 18, 1012 .

Hutter, A. M., Dinsmore, R. E., Willerson, J. T., and De Sanctis, R. W. (197I). Early systolic clicks due to mitral valve prolapse. Circulation, 44, 516 .

Kanarek, K. S., Bloom, K. R., Lakier, J. B., Pocock, W. A. and Barlow, J. B. (1973). Clinical aspects of submitral left ventricular aneurysms. South African Medical fournal, 47, 1225 .

Lakier, J. B., Fritz, V. U., Pocock, W. A., and Barlow, J. B. (I972a). Mitral components of the first heart sound. British Heart fournal, 34, 160.

Lakier, J. B., Kinsley, R. H., Pocock, W. A., and Barlow,
J. B. (1972b). Left atrial c wave and mitral leaflet size. Cardiovascular Research, 6, 585 .

Lakier, J. B., Pocock, W. A., Gale, G. E., and Barlow, J. B. (I972C). Haemodynamic and sound events preceding first heart sound in mitral stenosis. British Heart fournal, 34, II52.

Leatham, A. (1954). Splitting of the first and second heart sounds. Lancet, 2, 607.

Leatham, A. (1970). Auscultation of the Heart and Phonocardiography, pp. 17 and 26. J. and A. Churchill, London.

Leatham, A., and Gray, I. (1956). Auscultatory and phonocardiographic signs of atrial septal defect. British Heart fournal, 18, 193.

Lopez, J. F., Linn, H., and Shaffer, A. B. (1962). The apical first heart sound as an aid in the diagnosis of atrial septal defect. Circulation, 26, 1296.

Luisada, A. A., Kurz, H., Slodki, S. J., MacCanon, D. M., and Krol, B. (1967). Normal first heart sounds with nonfunctional tricuspid valve or right ventricle. Circulation, 35, II9.

Luisada, A. A., MacCanon, D. M., Coleman, B., and Feigen, L. P. (197I). New studies on the first heart sound. American fournal of Cardiology, 28, 140.

McDonald, A., Harris, A., Jefferson, K., Marshall, J., and McDonald, L. (I97I). Association of prolapse of posterior cusp of mitral valve and atrial septal defect. British Heart fournal, 33, 383.

McKusick, V. A. (1958). Cardiovascular Sound in Health and Disease, p. 348. Williams and Wilkens, Baltimore.

Pocock, W. A., and Barlow, J. B. (197I). An association between the billowing posterior mitral leaflet syndrome and congenital heart disease, in particular by atrial septal defect (annotation). American Heart fournal, 81, 720.

Pocock, W. A., Tucker, R. B. K., and Barlow, J. B. (1969). Mild Ebstein's anomaly. British Heart fournal, 31, 327.

Rawlings, M. S. (1960). The 'straight back' syndrome. A new cause of pseudoheart disease. American fournal of Cardiology, 5, 333.

Rees, A., Farru, O., and Rodriguez, R. (1972). Phonocardiographic, radiological, and haemodynamic correlation in atrial septal defect. British Heart fournal, 34, 781.

Sainani, G. S., Bruce, D. W., MacCanon, D. M., and Luisada, A. A. (1968). Respiratory alterations of the components of the first heart sound. Cardiologia, 52, 252.

Shah, P. M., Mori, M., MacCannon, D. M., and Luisada, A. A. (1963). Hemodynamic correlates of the various components of the first heart sound. Circulation Research, 12, 386.

Van Bogaert, A. (1968). Role of the valves in the genesis of normal heart sounds. Cardiologia, 52, 330.

Wooley, C. F., Klassen, K. P., Leighton, R. F., Goodwin, R. S., and Ryan, J. M. (1968). Left atrial and left ventricular sound and pressure in mitral stenosis. Circulation, 38, 295.

Requests for reprints to Professor J. B. Barlow, Department of Medicine, General Hospital, Johannesburg, South Africa. 